\title{
Total Correction of Tetralogy of Fallot: Effect of Transannular Patch on Early Outcome
}

\author{
Md.Azizul Islam Khan¹, Kazi Abul Hasan², A B M Abdus Salam³, Quazi Abul Azad, Sadia Sajmin \\ Siddiqua ${ }^{5}$, Md.Zahidul Islam ${ }^{1}$, Saira Khan ${ }^{6}$, Md.Sajedul Bari $^{1}$ \\ ${ }^{1}$ Department of Cardiac Surgery, NICVD, Dhaka, ${ }^{2}$ Department of Paediatric Cardiac Surgery, \\ NICVD, Dhaka, ${ }^{3}$ Department of Paediatric Cardiology, NICVD, Dhaka, ${ }^{4}$ Department of \\ Cardiovascular Surgery, NICVD, Dhaka, ${ }^{5}$ Sarkari Karmachari Hospital,Dhaka, ${ }^{6}$ Department of \\ Paediatrics, Marks Medical College,Dhaka
}

Key words: Tetralogy of Fallot, Pulmonary regurgitation, Right ventricular function.

\begin{abstract}
Background: It is arguable whether presence of transannular patch is itself a risk factor for adverse outcome at total correction(repair) of tetralogy of Fallot (TOF). This study intended to compare early outcome of intact pulmonary valve annulus with transannular patching at repair of TOF.

Methods: This prospective observational study was conducted from July 2015 to January 2017.40 patients were enrolled in 2 groups- $A \&$ B.In group A,14 patients with intact pulmonary valve annulus\& in group $B, 26$ patients with transannular patch. The diameter of pulmonary valve annulus was measured with Hegar dilator and $\boldsymbol{Z}$ value of the measured diameter were calculated from an established published nomogram. Transannular patch was placed if $\boldsymbol{Z}$ value of annular diameter $<-3$ or post repair operative room right ventricle/left ventricle pressure ratio $\left(\boldsymbol{P}_{\boldsymbol{R} V / L V}\right)>0.7$.Patients were monitored in the intensive care unit(ICU) and followed up for 3 months following discharge from hospital.

Results: Patients of group B were younger and smaller body surface area. There were no significant difference of preoperative variables in terms of peripheral arterial oxygen saturation $\left(\mathrm{S}_{p} \mathrm{O}_{2} \%\right)$, haematocrit $(\%)$, NYHA functional class, right ventricular hypertrophy, and level \& severity of right ventricular out flow tract obstruction. Early out come in terms of duration of ventilation time, inotrope support \& ICU stay; post operative morbidity \& mortality were more in group B than group A patients. Pulmonary regurgitation \& right ventricular dysfunction following transannular patch at repair of TOF plays important role for adverse outcome.
\end{abstract}

Conclusion: Transannular patch is associated with higher morbidity and mortality in total correction of Tetralogy of Fallot.

(Cardiovasc. j. 2018; 10(2): 194-200)

\section{Introduction:}

Tetralogy of Fallot is one of the most common congenital cardiac malformations. It can be present in 6 to 8 infants for every 10000 births. Stensen first described Tetralogy of Fallot in 1672.But Etinne - Louis Arthur Fallot in 1888 first described the clinical and complete pathological manifestations of Tetralogy of Fallot. ${ }^{1}$ The condition usually presents with cyanosis shortly after birth, attracting early medical attention. Presentation and survival of uncorrected TOF is influenced by the severity of the anatomic defect.25\% of surgically uncorrected infants die in the first year of life, $40 \%$ are dead by age $3,70 \%$ by age 10 and $95 \%$ by age 40 . Instantaneous risk of death is greatest in the first year of life. Risk then stays constant until about age 25, when it begins again to increase. ${ }^{2}$

Nearly all patients are candidates for surgery. Several options exist, either palliative procedure or total correction(repair). Goals of total correction are to close the ventricular septal defect and relief of right ventricular out flow obstruction. ${ }^{2}$ The most common problem after repair of TOF is right ventricular dysfunction. Pulmonary regurgitation, residual right ventricular outflow obstruction and ventricular septal defect plays important roles for the dysfunction of right ventricle. ${ }^{3}$ Pulmonary regurgitation is usually caused by placement of transannular patch. The resulting pulmonary regurgitation is very well tolerated by some individuals. But some individuals do not tolerate pulmonary regurgitation and may develop the

Address of Correspondence: Dr. Md. Azizul Islam Khan, Department of Cardiac surgery. National Institute of Cardiovascular Diseases, Dhaka, Bangladesh. Email: drkhanazizulislam@gmail.com 
sequel of right ventricular dysfunction like poor functional status, arrhythmias and sudden death. ${ }^{4}$

\section{Methods:}

This prospective observational study carried out in the Department of Cardiac Surgery, National Institute of Cardiovascular Diseases, Dhaka from July 2015 to January 2017.The study were conducted with signed informed consent of participants/guardians accordingly. Total 40 patients were enrolled in this study. Patients were divided in two groups. Patients with intact pulmonary valve annulus in group A \& patients with transannular patch were in group B. Tetralogy of Fallot patients with congenital pulmonary atresia, aortic stenosis , mitral stenosis \& with intractable 'tet' spell that cannot be controlled despite aggressive intensive care unit care were excluded from the study. The patients were evaluated by detail history, clinical examination \& relevant investigations.

\section{Operative procedure:}

A uniform operating technique was used. After median sternotomy \& pericardiotomy external anatomy of the heart \& great vessels were studied with particular attention to right ventricle (RV), main pulmonary artery (MPA)\& its branches and courses of coronary arteries. With aorto-bicaval cardiopulmonary bypass (CPB), moderate hypothermia \& antegrade cold blood cardioplegia transatrial-transpulmonary approach was used. Hegar dilators were introduced to the right ventricular out flow tract and diameter calibrated according to size of the Hegar dilator that snugly fit. The resection of infundibular bands, fibrous thickenings and in some cases pulmonary valvotomy done. Thickened pulmonary cusps edges were excised if needed to relieve stenosis. Hegar dilator again introduced to the right ventricular out flow tract
(RVOT) and diameter of the pulmonary valve annulus were measured. Z values of the measured annular diameter were calculated from an established published nomogram. ${ }^{3}$ Generally a transannular patch was not placed if Zvalue of the annular diameter was larger than -3. The VSD was closed with poly tetra fluoro ethylene (PTFE) patch. After repair, with cannulae for CPB still in place, post repair operative room right ventricle/left ventricle pressure ratio $\left(\mathrm{P}_{\mathrm{RV} / \mathrm{LV}}\right)$ was obtained. If $\mathrm{P}_{\mathrm{RV} / \mathrm{LV}}$ was greater than $0.7 \&$ transannular patch was not given, then CPB was reestablished and transannular patch was given. When transannular patch was placed and the ratio $>0.8$ then the site of stenosis was localized by pressure manometry and the situation was corrected by giving long patch beyond stenosed area. If no correctable cause of elevation of $\mathrm{P}_{\mathrm{RV} /}$ $\mathrm{LV}$ and if patient's condition remains good, the patient was sent to ICU with continuous monitoring of RV pressure. If patients condition in operating room not good or RV pressure becomes considerably elevated above left a $4 \mathrm{~mm}$ fenestration made on the VSD patch.

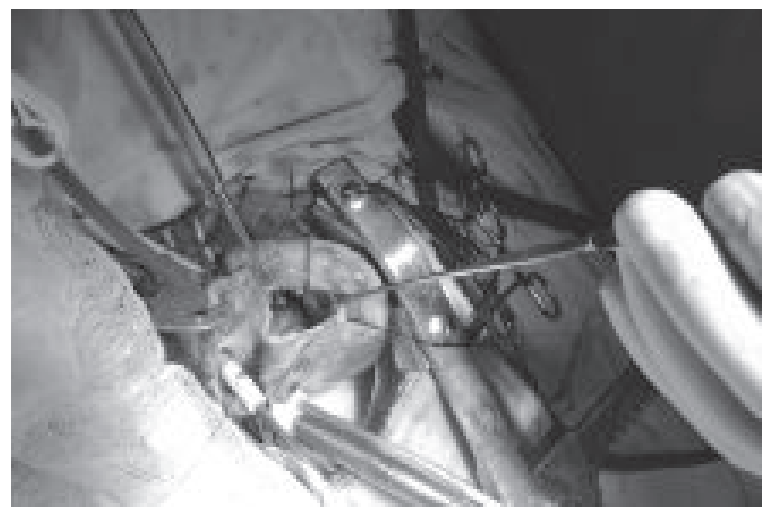

Fig.-1: Transatrial/transpulmonary approach of repair.
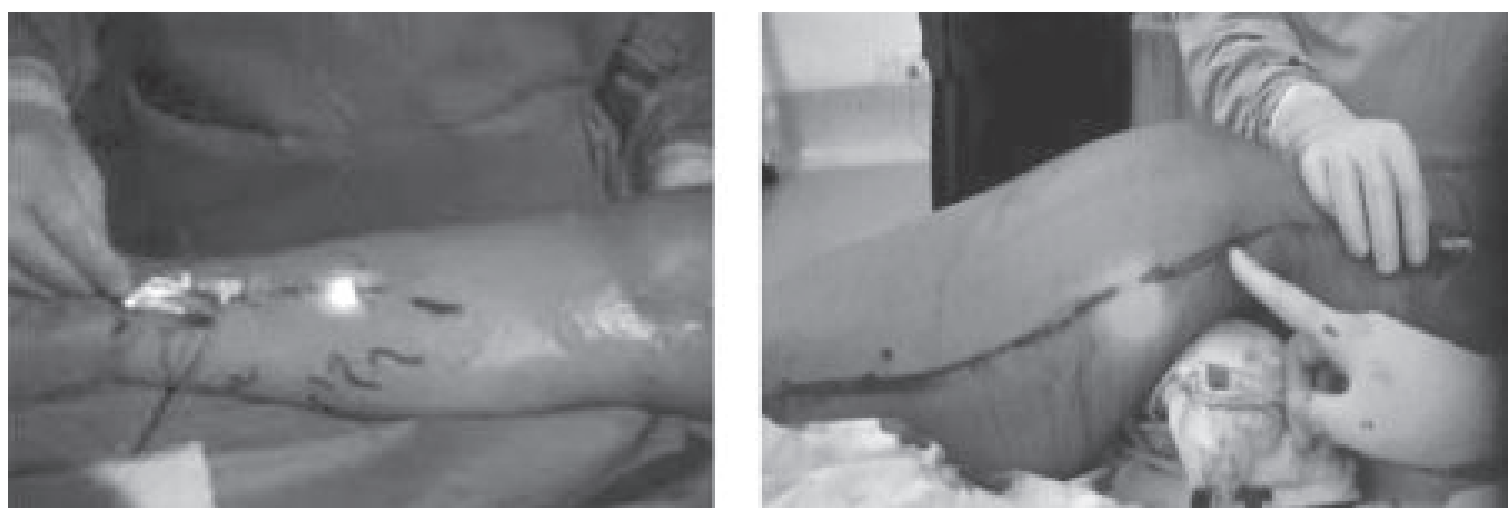

Fig.-2: Hegar dilator to measure pulmonary valve annulus diameter. 


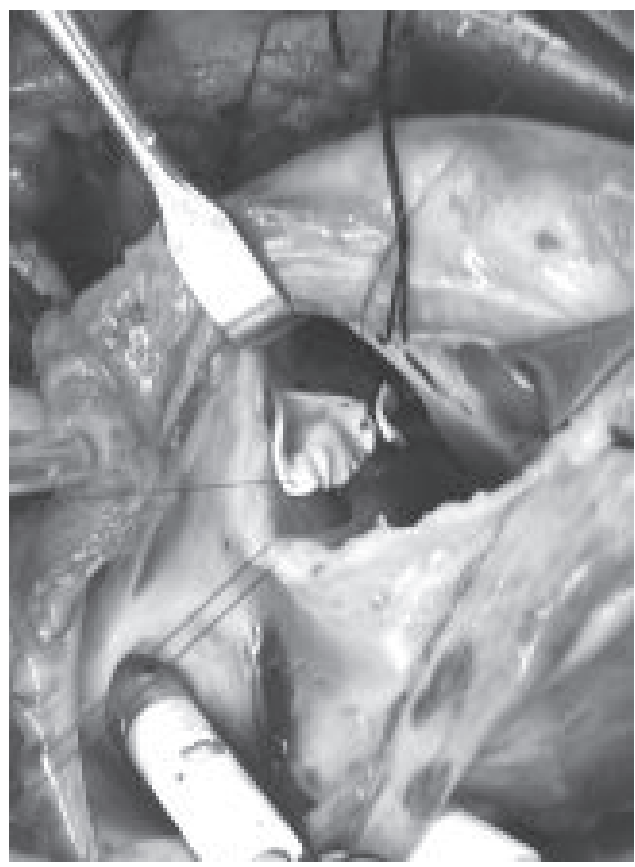

Fig.-3: VSD closure with PTFE patch.

Following above mentioned uniform operating technique 26(65\%) patients needed transannular patch comprising the group B. Patients were taken to ICU after operation. They were all on ventilator with inotrope support. Ventilation time, duration of inotrope support, ICU stay, complications if any were treated and recorded. In hospital mortality were also recorded. Patients were followed up at $1 \& 3$ months after discharge.

Data were collected by use of interview schedule and from relevant investigations. Data were entered into a computer and data file was constructed. Data were analyzed by Statistical Programme for Social Science(SPSS).Data were verified by students 't' test (continuous variable)\&chi-square test (categorical variable).Probability value of $<0.05$ were considered significant.

\section{Results:}

In this study it revealed that patients of group $\mathrm{B}$ are younger and smaller body surface area though statistically not significant. Preoperative clinical and investigation findings in terms of NYHA functional class, $\mathrm{S}_{\mathrm{P}} \mathrm{O}_{2} \%$, haematocrit (Hct\%), cardiothoracic ratio, cardiac rhythm, right ventricular hypertrophy, level and severity

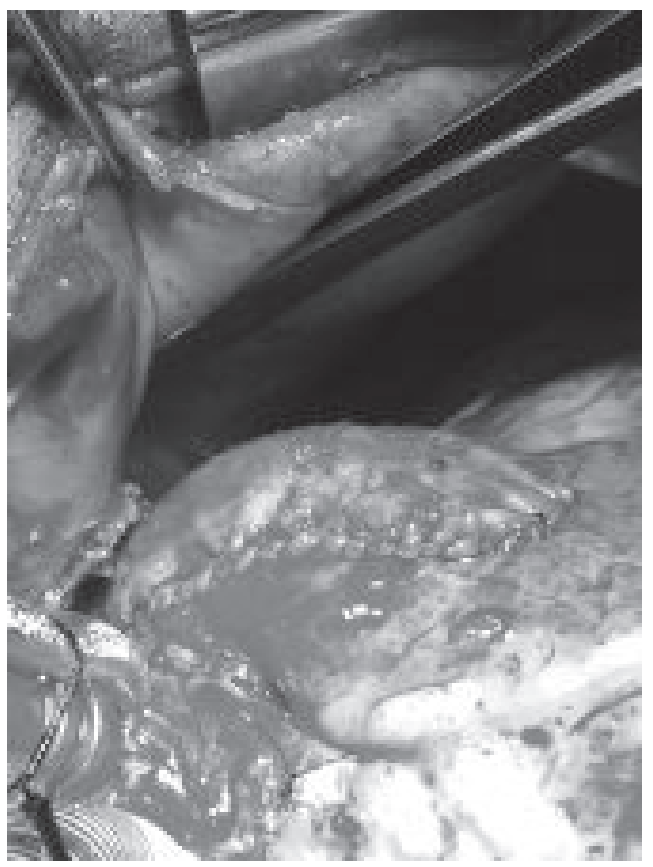

Fig.-4: Long transannular patch in situ.

of right ventricular outflow obstruction were not significantly different among the groups.

Difference of pre repair $\mathrm{RV}$ to $\mathrm{PA}$ pressure gradient, $\mathrm{RV} / \mathrm{LV}$ pressure ratio, $\mathrm{Z}$ value of pulmonary valve annulus were not statistically significant between the groups. Post repair RV to $\mathrm{PA}$ pressure gradient, $\mathrm{RV} / \mathrm{LV}$ pressure ratio were also not significantly different among the groups. Aortic cross clamp time, extracorporeal circulation time, ventilation time, duration of inotrope support and ICU stay were significantly longer in group B than group A. Post operative in hospital morbidity and mortality were also more in group B than group $\mathrm{A}$.

No patients died up to 3 months follow up. At 1 and 3 month follow up there were no significant difference in NYHA functional class and RVOT gradient among the groups but mild to moderate pulmonary regurgitation were significantly more in group B than group A. There was no residual or recurrent VSD among the groups. None of the patients had RV dysfunction at 1 and 3 month follow up in group A comparing 5(21.7\%) had mild\& $1(4.3 \%)$ patients had moderate RV dysfunction at 1 month follow up and at 3 month follow up 3(13.1\%) had mild \& $1(4.3 \%)$ moderate $\mathrm{RV}$ dysfunction in group B patients. 
Table-I

Preoperative characteristics of study population $(n=40)$.

\begin{tabular}{|c|c|c|c|}
\hline Variable & Group $\mathrm{A}(\mathrm{n}=14)$ & GroupB(n=26) & $\mathrm{p}$ value \\
\hline Age in years(mean $\pm \mathrm{SD})$ & $8.6 \pm 4.8$ & $7.0 \pm 2.9$ & $0.272^{\mathrm{NS}}$ \\
\hline Body surface area in $\mathrm{m}^{2}($ mean $\pm \mathrm{SD})$ & $0.89 \pm 0.32$ & $0.73 \pm 0.15$ & $0.089^{\mathrm{NS}}$ \\
\hline NYHA functional class (\%) & & & $0.684^{\mathrm{NS}}$ \\
\hline Class II $\quad 9(64.3)$ & $15(57.7)$ & & \\
\hline Class III $\quad 5(35.7)$ & $11(42.3)$ & & \\
\hline $\mathrm{Sp}_{\mathrm{a}} \mathrm{O}_{2}$ in $\%($ mean $\pm \mathrm{SD})$ & $80.0 \pm 1.0$ & $79.8 \pm 2.2$ & $0.718^{\mathrm{NS}}$ \\
\hline Haematocrit (\%) (mean \pm SD $)$ & $43.5 \pm 2.9$ & $44.6 \pm 3.4$ & $0.324^{\mathrm{NS}}$ \\
\hline X-ray chest -cardio thoracic ratio(mean \pm SD) & $0.496 \pm 0.011$ & $0.499 \pm 0.013$ & $0.457^{\mathrm{NS}}$ \\
\hline Electrocardiogram & & & \\
\hline Rhythm -Normal (\%) & $14(100 \%)$ & $26(100 \%)$ & - \\
\hline RVH - Present (\%) & $14(100 \%)$ & $26(100 \%)$ & - \\
\hline Echocardiogram & & & \\
\hline Pulmonary valve annulus in $\mathrm{mm}($ mean $\pm \mathrm{SD})$ & $12.2 \pm 1.2$ & $11.0 \pm 2.4$ & $0.098^{\mathrm{NS}}$ \\
\hline Main pulmonary artery in mm (mean \pm SD) & $13.1 \pm 1.2$ & $11.7 \pm 2.6$ & $0.064^{\mathrm{NS}}$ \\
\hline Right pulmonary artery in $\mathrm{mm}($ mean $\pm \mathrm{SD})$ & $8.1 \pm 0.8$ & $7.7 \pm 1.4$ & $0.311^{\mathrm{NS}}$ \\
\hline Left pulmonary artery in mm (mean \pm SD) & $7.6 \pm 0.5$ & $7.2 \pm 1.1$ & $0.145^{\mathrm{NS}}$ \\
\hline RVOT gradient in mmHg(mean $\pm \mathrm{SD})$ & $66.7 \pm 8.1$ & $70.5 \pm 10.6$ & $0.248^{\mathrm{NS}}$ \\
\hline
\end{tabular}

$\mathrm{SD}=$ Standard deviation; $\mathrm{S}=$ Significant; $\mathrm{NS}=$ Not significant;

NYHA=New York Heart Association; RVH=Right ventricular hypertrophy; RVOT=Right ventricular out flow tract.

Table-II

Per operative characteristics of study population $(n=40)$.

\begin{tabular}{lccc}
\hline Variable & $\begin{array}{c}\text { Group A } \\
(\mathrm{n}=14)\end{array}$ & $\begin{array}{c}\text { Group B } \\
(\mathrm{n}=26)\end{array}$ & p value \\
\hline Pre repair RV to PA pressure gradient(mean $\pm \mathrm{SD})$ & $76.7 \pm 8.1$ & $80.5 \pm 10.6$ & $0.248^{\mathrm{NS}}$ \\
Pre repair RV/LV pressure ratio(mean $\pm \mathrm{SD})$ & $1.0 \pm 0.02$ & $1.0 \pm 0.05$ & $0.399^{\mathrm{NS}}$ \\
Pulmonary valve annulus Z value(mean $\pm \mathrm{SD})$ & $-2.8 \pm 0.19$ & $-3.8 \pm 1.76$ & $0.054^{\mathrm{NS}}$ \\
Aortic cross clamp time-min.(mean $\pm \mathrm{SD})$ & $65.1 \pm 13.7$ & $74.1 \pm 14.8$ & $0.004^{\mathrm{S}}$ \\
Extracorporeal circulation time-min.(mean $\pm \mathrm{SD})$ & $104.7 \pm 22.0$ & $124.4 \pm 17.9$ & $0.020^{\mathrm{S}}$ \\
Post repair RV/LV pressure ratio(mean $\pm \mathrm{SD})$ & $0.51 \pm 0.09$ & $0.48 \pm 0.08$ & $0.447^{\mathrm{NS}}$ \\
Post repair RV to PA pressure gradient(mean $\pm \mathrm{SD})$ & $26.5 \pm 2.7$ & $25.0 \pm 2.1$ & $0.062^{\mathrm{NS}}$ \\
\hline
\end{tabular}

$\mathrm{RV}=$ Right ventricle; $\mathrm{PA}=$ Pulmonary artery; $\mathrm{LV}=$ Left ventricle.

$\mathrm{P}$-value from Students-t test; $\mathrm{S}=$ Significant; NS= Not significant.

Table-III

Post operative in hospital characteristic of study population $(n=40)$.

\begin{tabular}{lccc}
\hline Variable & Group A & Group B & p value \\
\hline Ventilation time -hours(mean \pm SD) & $15.9 \pm 5.2$ & $22.4 \pm 11.5$ & $0.055^{\mathrm{NS}}$ \\
Duration of inotrope support-hours(mean \pm SD) & $62.2 \pm 25.2$ & $96.7 \pm 38.0$ & $0.006^{\mathrm{S}}$ \\
ICU stay-hours(mean \pm SD) & $93.7 \pm 27.9$ & $129.4 \pm 52.7$ & $0.029^{\mathrm{S}}$ \\
Mortality & None $(0 \%)$ & $3(11.5 \%)$ & - \\
Morbidity & & & \\
Low cardiac out put & None $(0 \%)$ & $3(11.5 \%)$ & - \\
\multicolumn{1}{c}{ Arrhythmia $\quad 2(14.3 \%)$} & $4(15.4 \%)$ & - \\
$\quad$ Renal dysfunction & None $(0 \%)$ & $1(3.8 \%)$ & - \\
\hline
\end{tabular}

ICU=Intensive Care Unit.

P-value from Students-t test; $\mathrm{S}=$ Significant; NS= Not significant. 


\section{Table-IV}

Comparison of NYHA functional class at follow-up of study population ( $n=40)$.

\begin{tabular}{lccc}
\hline NYHA functional class & $\begin{array}{c}\text { Group A (n=14) } \\
\text { Freq. (\%) }\end{array}$ & $\begin{array}{c}\text { Group B(n=23) } \\
\text { Freq. (\%) }\end{array}$ & p value \\
\hline At 1 month follow up & & & $0.389^{\text {NS }}$ \\
Class I 11(78.6) & $15(65.2)$ & & \\
Class II & $3(21.4)$ & $8(34.8)$ & $0.769^{\text {NS }}$ \\
At 3 month follow up & & & \\
& $14(100)$ & $21(91.1)$ & \\
& $0(0)$ & $2(8.9)$ & \\
\hline
\end{tabular}

NYHA $=$ New York Heart Association.

p-value from Chi-squared test; NS= Not significant.

Table-V

Comparison of pulmonary regurgitation \& RVOT gradient: at follow-up.

\begin{tabular}{lccc}
\hline $\begin{array}{l}\text { Variable } \\
\text { Pulmonary regurgitation }\end{array}$ & $\begin{array}{c}\text { Group A(n=14) } \\
\text { Frequency (\%) }\end{array}$ & $\begin{array}{c}\text { Group B(n=23) } \\
\text { Frequency (\%) }\end{array}$ & pValue \\
\hline At 1 month follow up & & & \\
None & $10(71.44)$ & $0(0.0)$ & $0.027^{\mathrm{S}}$ \\
Mild & $2(14.28)$ & $11(47.82)$ & $0.015^{\mathrm{S}}$ \\
Moderate & $2(14.28)$ & $12(52.18)$ & - \\
$\quad$ At 3 month follow up & $12(85.72)$ & & $0.027^{\mathrm{S}}$ \\
$\quad$ None & $2(14.28)$ & $11(47.82)$ & - \\
Mild & $0(0.0)$ & $12(52.18)$ & \\
Moderate & Mean $\pm \mathrm{SD}$ & Mean $\pm \mathrm{SD}$ & $0.949^{\mathrm{NS}}$ \\
RVOT gradient & $10.4 \pm 3.6$ & $10.3 \pm 4.0$ & $0.950^{\mathrm{NS}}$ \\
$\quad$ At 1month follow up & $10.0 \pm 3.2$ & $10.1 \pm 3.8$ & \\
At 3month follow up &
\end{tabular}

RVOT=Right ventricular out flow tract; P-value for pulmonary regurgitation reached from Chi-squared test; P-value for RVOT gradient from Student's t-test.

$\mathrm{S}=$ Significant; NS=Not significant.

\section{Table-VI}

Comparison of right ventricular dysfunction at follow-up of study population $(n=40)$.

\begin{tabular}{cccc}
\hline $\begin{array}{l}\text { RV dysfunction } \\
\text { At } 1 \text { month follow up }\end{array}$ & $\begin{array}{c}\text { Group } \mathrm{A}(\mathrm{n}=14) \\
\text { freq. }(\%)\end{array}$ & $\begin{array}{c}\text { GroupB(n=23) } \\
\text { freq. }(\%)\end{array}$ & p value \\
\hline None & $14(100)$ & $17(74)$ & $0.052^{\mathrm{NS}}$ \\
Mild & $0(0.0)$ & $5(21.7)$ & - \\
Moderate & $0(0.0)$ & $1(4.3)$ & - \\
At 3 month follow up & & & $0.274^{\mathrm{NS}}$ \\
None & $14(100)$ & $19(82.6)$ & - \\
Mild & $0(0.0)$ & $3(13.1)$ & - \\
Moderate & $0(0.0)$ & $1(4.3)$ & \\
\hline
\end{tabular}

$\mathrm{RV}=$ Right ventricle; $\mathrm{P}$-value from Chi-squared test.

NS=Not significant. 


\section{Discussion:}

Total correction (repair) is the definitive treatment of TOF. Age at repair, body surface area, haematocrit level, severity of right ventricular(RV) and pulmonary artery(PA)outflow obstruction, other associated cardiac malformations, previous operation ,operative procedure used like transannular patch required or not along with post repair right ventricle/left ventricle( $\mathrm{RV} / \mathrm{LV}$ ) pressure ratio are important variables affect the outcome after repair of TOF. The normal range of the $\mathrm{Z}$ value of the dimensions of right ventricular outflow tract and pulmonary trunk along with its branches at all level is -2 to +2 .Any value less than -2 is abnormally small. ${ }^{3}$ Apparently the pulmonary regurgitation allowed by a transannular patch and the increase in $R V$ volume are usually (unless post repair $\mathrm{P}_{\mathrm{RV} / \mathrm{LV}}$ is high) well tolerated acutely, chronically and late postoperatively upto about 20 years by the previously hypertrophied right ventricle. ${ }^{5}$ Restrictive right ventricular physiology(defined as antegrade pulmonary artery flow in late diastole) is more common after transannular patch repair of right ventricular out flow obstruction. In early post operative period restricted right ventricular physiology is associated with low cardiac output, effusions and a prolonged post operative course. ${ }^{6}$ Use of a transannular patch becomes fully expressed risk only in those patients with restrictive pulmonary arteries or isolated branch stenosis. This is because it decreases the force, the ventricle can generate in maintaining the cardiac output. ${ }^{7}$ The pulmonary valve participate in somatic growth due to stimulating effect of relative increase in post repair antegrade flow of blood across the right ventricular outflow tract. This result in a regression of right ventricular outflow tract obstruction with time. ${ }^{8}$

There is a long lasting impaired hemodynamics in patients undergoing repair of TOF in adult. The impaired left ventricular function could be explained by the fibrosis following prolonged cyanosis, with consequent chronic myocardial hypoxaemia and by altered contraction of the interventricular septum due to presence of a prosthetic patch. ${ }^{9}$
98\% of patients are considered by themselves or their parents to be in New York Heart Association (NYHA) functional class I after repair of TOF for at least 20 years. Risk factors for impaired exercise tolerance are older age at repair(>12 years), residual right ventricular hypertension, pulmonary valve regurgitation and residual or recurrent ventricular septal $\operatorname{defect}(\mathrm{VSD}) .{ }^{10} \mathrm{In}$ hospital mortality is $2 \%$ to $5 \%$ after total correction of TOF. Most of the causes of in hospital death are cardiac failure, pulmonary failure, haemorrhage, arrhythmia, neurogenic and multiorgan failure. ${ }^{3,12,13}$

Age range and body surface area of patients of this series are higher than some other series in advanced centers where most of the patients are under 5 years. ${ }^{4,12-15}$ This may be a reflection of better perioperative care of pediatric cardiac patients in advanced centers which is important for early operation. Percentage of patients (65\%) of this series needed transannular patch is consistent with some series. $8,14,16-18$ Longer duration of mechanical ventilation, inotrope support, ICU stay \& more morbidity in group B patients as it is seen other studies, 6,8,10,19 may be due to restricted right ventricular physiology which is more common after transannular patch. ${ }^{20}$ Post operative morbidity of patients of this series are consistent with other series. ${ }^{6,8} \mathrm{As}$ a whole the in hospital mortality (7.5\%)seen in this study is high in comparison to some recent studies where it varies between $2 \%$ to $5 \% .{ }^{11,21-23}$ In some older studies mortality was higher(12\%). ${ }^{3,24}$ Gradual decrease of mortality in recent period is reflection of improved cardiopulmonary bypass technology as well as surgical techniques and perioperative care. ${ }^{3}$ The patient dead all were in group B, due to low cardiac output and its sequelae. The cause of death follows the causes of death with other series. ${ }^{13}$ Transannular patch may have a deleterious effect in conjunction with younger age and smaller body surface area in this group B patients.

At follow up significantly higher percentage of patients with pulmonary regurgitation due to transannular patch in group B patients may contributed the higher percentage(but not statistically significant; may be due to small sample size) of mild to moderate RV dysfunction in this group. Pulmonary regurgitation and $R V$ dysfunction in group B may be responsible for poor 
functional response in terms of NYHA functional class as it is seen in other studies. ${ }^{11,13,25-28}$

\section{Conclusion:}

Repair of Tetralogy of Fallot has acceptable morbidity and mortality rates. Early outcome with intact pulmonary valve annulus is better than that of transannular patching. Attempts should be made for the preservation of pulmonary valve annulus. Optimum perioperative care is important for better outcome.

\section{Conflict of Interest - None.}

\section{References:}

1. Ungerleider RM. Tetralogy of Fallot. In: Sabiston DC, Spencer FC. Eds. Surgery of The Chest. Philadelphia: WB Saunders Company, USA,1996: 1464-1492.

2. Bertranou EG, Blackstone EH, Hazelrig JB, Turner ME, Kirklin JW. Life expectancy without surgery in Tetralogy of Fallot. Am J Cardiol 1978; 42:458.

3. Kouchoukos NT, Blackstone EH, Doty DB, Hanley FL, Karp RB. Ventricular Septal Defect with Pulmonary Stenosis or Atresia. In: Kirklin/ Barratt-Boyes Cardiac Surgery. Philadelphia: Elsevier Science, 2012:1359-1467.

4. Bojar RM, Warner KG. Common post operative scenarios. In: Manual of Perioperative Care in Cardiac Surgery. Massachusetts: Black Well Science, 1999; 563-576.

5. Mulla N, Simpson P, Sullivan NM, Paridon SM. Determinants of aerobic capacity during exercise following complete repair of tetralogy of Fallot with a transannular patch. Pediator Cardiol1997; 18:350-357.

6. Norgard G, Gatzoulis MA, Moraes F, Lincoln C, Shore D, Shinebourne FA, Redington AN. Relationship between type of out flow tract repair and post operative right ventricular diastolic physiology in tetralogy of Fallot. Circulation1996; 94:3276-3280.

7. Rizzoli G, Mazzucco A, Bromana T, Stellin G, Livi U, Figgian G, et al. The risk of surgical treatment of tetralogy of Fallot: an appraisal. Int J Cardiol 1985; 9:726 .

8. Rao V, Kadletz M, Hornberger LK, Freedom RM, Black MD. Preservation of pulmonary valve complex in tetralogy of Fallot: How small is too small. Ann Thorac Surg 2000; 69:176-180.

9. Presbitero P, Demeric D, Aruta E, Villani M, Dismma M, Ottino GM . Results of total correction of tetralogy of Fallot performed in adults. Ann Thorac Surg 1998; 61:1870-1873.

10. Kirklin JK, Kirklin JW, Blackstone EH, Milano A, Pacificio AD. Effect of transannular patching on out come after repair of tetralogy of Fallot. Ann Thorac Surg 1989; 48:201209.

11. Kirklin JW, Blackstone EH, Jonas RA, Shimazaki Y, Kirklin JK, Mayer JE, et al. Morphologic and surgical determinants of outcome events after repair of tetralogy of Fallot and pulmonary stenosis: a two institution study. J Thorac Cardiovasc Surg 1992; 103: 706-723.
12. Karl TR, Sano S, Pornviliwan S, Mee R. Tetralogy of Fallot: favorable outcome of non neonatal trans atrial trans pulmonary repair. Ann Thorac Surg 1992; 54:903-907.

13. Piccoli GP, Dickinson DF, Musumeci F, Hamilton DI.A changing policy for the surgical treatment of tetralogy of Fallot: early and late results in 235 consecutive patients. Ann Thorac Surg 1982; 33: 365-373.

14. Knott CJ, Elkins RC, Lane MM, Holz J, McCue C, Ward KE. A 26 years experience with surgical management of tetralogy of Fallot: risk analysis for mortality or late reintervention. Ann Thorac Surg 1998; 66:506-511.

15. Giannopoulos AK, Karros CP, Zavaropoulos P, Papagiannis J, Rammos S, Kirvassilis GV, et al. Early results after transatrial/ transpulmonary repair of tetralogy of Fallot. European Journal of Cardio-thoracic Surgery 2002; 22: 582-586.

16. Arciniegas E, Farooki ZQ, Hakimi M, Perry BL, Green EW. Early and late results of total correction of tetralogy of Fallot. J Thorac Cardiovasc Surg 1980; 88: 770-778.

17. Dietl CA,Torres AR,Cazzaniga ME, Favaloro RG. Right atrial approach for surgical correction of tetralogy of Fallot. Ann Thorac Surg 1989; 47:546-551.

18. Amorim S, Cruz C, Macedo F, Bastos PT, Goncaves FR. Tetralogy of Fallot: Prognostic factors after surgical repair. Rev Port Cardiol 2005; 24:845-855.

19. Ruijter FT, Weenink L, Hitchcock FJ, Meijboom EJ, Bennink GB. Right ventricular dysfunction and pulmonary valve replacement after correction of tetralogy of Fallot. Ann Thorac Surg 2002; 73:1974-1980.

20. Arsdell GS, Maharay GS, Tom RN, Rao VK, Coles JG, Freedom RM. What is the optimal age of repair of tetralogy of Fallot? Circulation 2000; 102:123-129.

21. Castaneda AR. Classical repair of tetralogy of Fallot: timing, technique and results. Semin Thorac Cardiovasc Surg 1990; 2:70.

22. Groh MA, Mcliones JN, Bove EL, Kirklin JW, Blackstone EH, Lupinetti FM. Repair of tetralogy of Fallot in infancy: effect of pulmonary artery size on outcome. Circulation 1991; 84(III):206.

23. Karl TR, Sano S, Pornviliwan S, Mee RB. Tetralogy of Fallot: favorable outcome of non neonatal transatrial, transpulmonary repair. Ann Thorac Surg 1992; 54:903.

24. John S, Sukumar IP, Cerian G, Gupta RP, Krisnaswamy S. Intracardiac repair in tetralogy of Fallot: haemodynamic status following corrective surgery. Circulation 1974; 119:958-960.

25. Delisle G, Olley PM. Submaximal effort test in children with Fallot's tetralogy before and after correction. Union Med Can 1974; 103:886.

26. Marx GR, Hicks RW, Allen HD, Goldberg SJ. Noninvasive assessment of hemodynamic responses to exercise in pulmonary regurgitation after operation to correct pulmonary outflow obstruction. Am J Cardiol 1988; 61:595.

27. Rowe SA, Zahka KG, Manolio TA, Horneffer PJ, Kidd. Lung function and pulmonary regurgitation limit exercise capacity in post operative tetralogy of Fallot. J Am Coll Cardiol 1991; 17:461.

28. Wessel HU, Cunningham WJ, Paul MH, Bastanier CK, Muster AJ, Idriss FS. Exercise performance in tetralogy of Fallot after intra cardiac repair. J Thorac Cardiovasc Surg 1980; 80:582. 